\title{
Severe digital necrosis as the clinical onset of antiphospholipid syndrome
}

\author{
José Antonio Vargas-Hitos ${ }^{1} \cdot$ José Mario Sabio $^{1} \cdot$ Nuria Navarrete-Navarrete $^{1} \cdot$ \\ Mónica Zamora-Pasadas $^{1} \cdot$ Juan Jiménez-Alonso ${ }^{1}$
}

Received: 23 September 2015/Accepted: 5 October 2015/Published online: 22 October 2015

(c) SIMI 2015

A 70-year-old man, non-smoker, presented with bilateral digital necrosis, which had developed over the prior month, related to an aggressive Raynaud's phenomenon of 2 months of evolution (Fig. 1a). The patient had no familial or personal history of previous thrombosis events, heart valve disease, livedo reticularis, nephropathy, thrombocytopenia or neurological manifestations. Upon examination, pulses were present, capillaroscopy was normal, and there was no sclerodactyly or skin sclerosis. Treatment with nifedipine, endovenous alprostidil, bosentan and analgesics was initiated with poor results. A complete blood count and biochemical tests, urinalysis, immunoglobulin, serum protein electrophoresis, cryoglobulin, serology for hepatitis $\mathrm{B}$ and $\mathrm{C}$, antinuclear and antineutrophil cytoplasmic antibodies were either normal (the platelet count was 160,000 per $\mathrm{mm}^{3}$ ) or negative. $18 \mathrm{~F}$ FDG PET-CT did not show tumours or large vessel vasculitis. A biopsy of the ischemic areas of the hands only indicated epidermic necrosis. A thrombophilia workup showed the patient to be heterozygous for the C677T polymorphism of the MTHFR gene and for factor XII and test positively for IgG anti- $\beta 2$-glycoprotein- 1 antibodies in two separate determinations made 12 weeks apart $(93.80$ and $205 \mathrm{U} / \mathrm{mL}$, respectively). Even though the genetic thrombophilia may have contributed to a procoagulant state, the severity of the lesions led us to consider the diagnosis of antiphospholipid syndrome (APS). Treatment with enoxaparin (60 mg/12 h) was started, and progressive

José Antonio Vargas-Hitos

joseantoniovh@hotmail.com

1 Systemic Autoimmune Diseases Unit, Internal Medicine Department, Virgen de las Nieves University Hospital, 9th Floor. Avda. Fuerzas Armadas N ${ }^{\circ}$ 2, 18014 Granada, Spain improvements in the pain and reperfusion of the base of the fingers were observed (Fig. 1b). The APS is a prothrombotic disorder characterized by the predisposition to venous
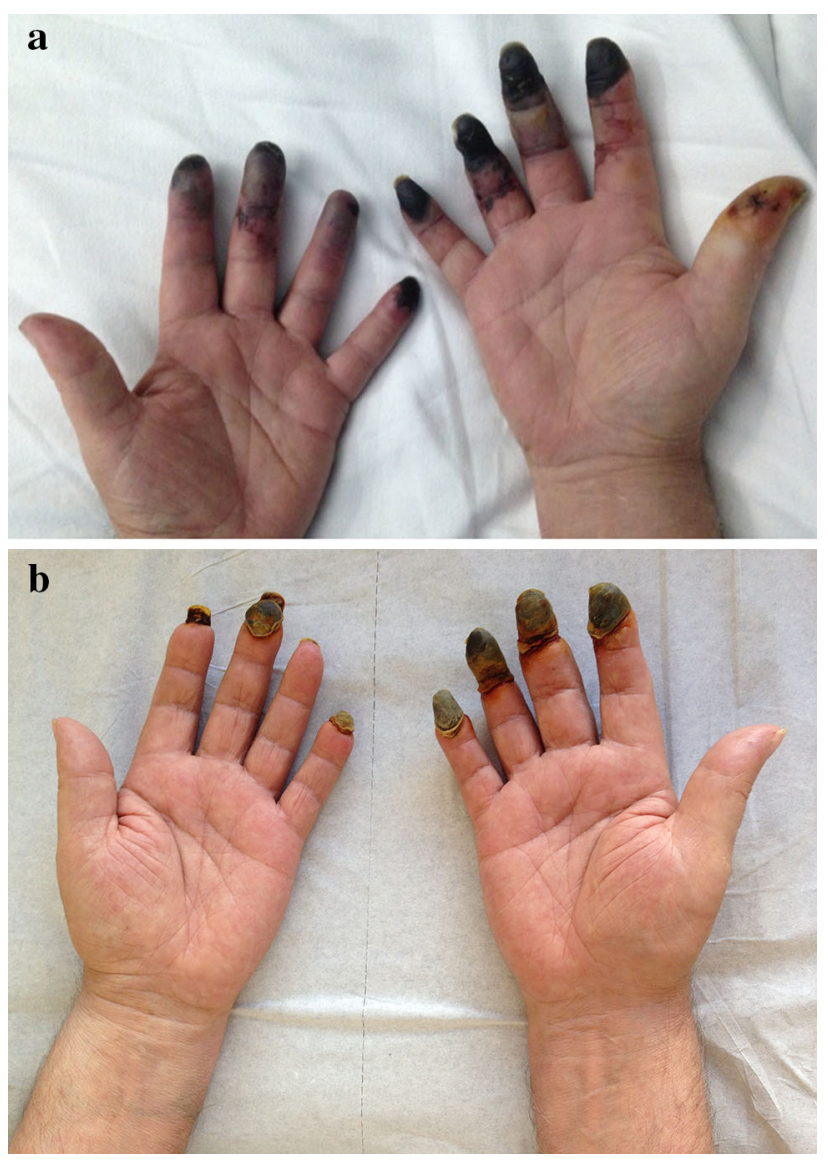

Fig. 1 a Bilateral digital necrosis at the time of presentation. b Improvement of the lesions after treatment with anticoagulants during 9 months 
or arterial thrombosis, and with an increased morbidity of pregnancy due to the presence of autoantibodies directed against certain types of phospholipids. Less frequently, APS should also be suspected when a patient presents with refractory headaches, unexplained nephropathy or heart valve disease, dementia or cognitive disorders, seizures, livedo reticularis or thrombocytopenia. Currently, to establish the diagnosis of APS, both a characteristic clinical presentation and detection of APS autoantibodies are necessary [1]. Concomitant thrombosis and necrosis of multiple fingers are unusual but previously reported manifestations of APS [2] that should be included in the differential diagnosis of digital necrosis along with systemic sclerosis, gammopathies, paraneoplastic syndromes, Buerger's disease, cryoglobulinemia, systemic vasculitis, cholesterol crystal embolism and thrombophilias (normally associated with other procoagulant conditions) [3].

\section{Compliance with ethical standards}

Conflict of interest The authors declare that they have no conflict of interest.
Statement of human and animal rights The procedures followed were in accordance with the ethical standards of the responsible committee on human experimentation.

Informed consent Informed consent was obtained from all individual participants included in the study.

\section{References}

1. Miyakis S, Lockshin MD, Atsumi T, Branch DW, Brey RL, Cervera $\mathrm{R}$ et al (2006) International consensus statement on an update of the classification criteria for definite antiphospholipid syndrome (APS). J Thromb Haemost 4:295-306

2. Gonzalez ME, Kahn P, Price HN, Kamino H, Schaffer JV (2011) Retiform purpura and digital gangrene secondary to antiphospholipid syndrome successfully treated with sildenafil. Arch Dermatol 147:164-167

3. Abdallah M, Hamzaoui S, Larbi T, Bouslama K, Harmel A, Ennafaa $M$ et al (2010) Etiological profile of digital necrosis of the upper limbs: analysis of 25 cases. J Mal Vasc 35:12-16 